International Journal of

Health, Medicine and

Nursing Practice

(IJHMNP)

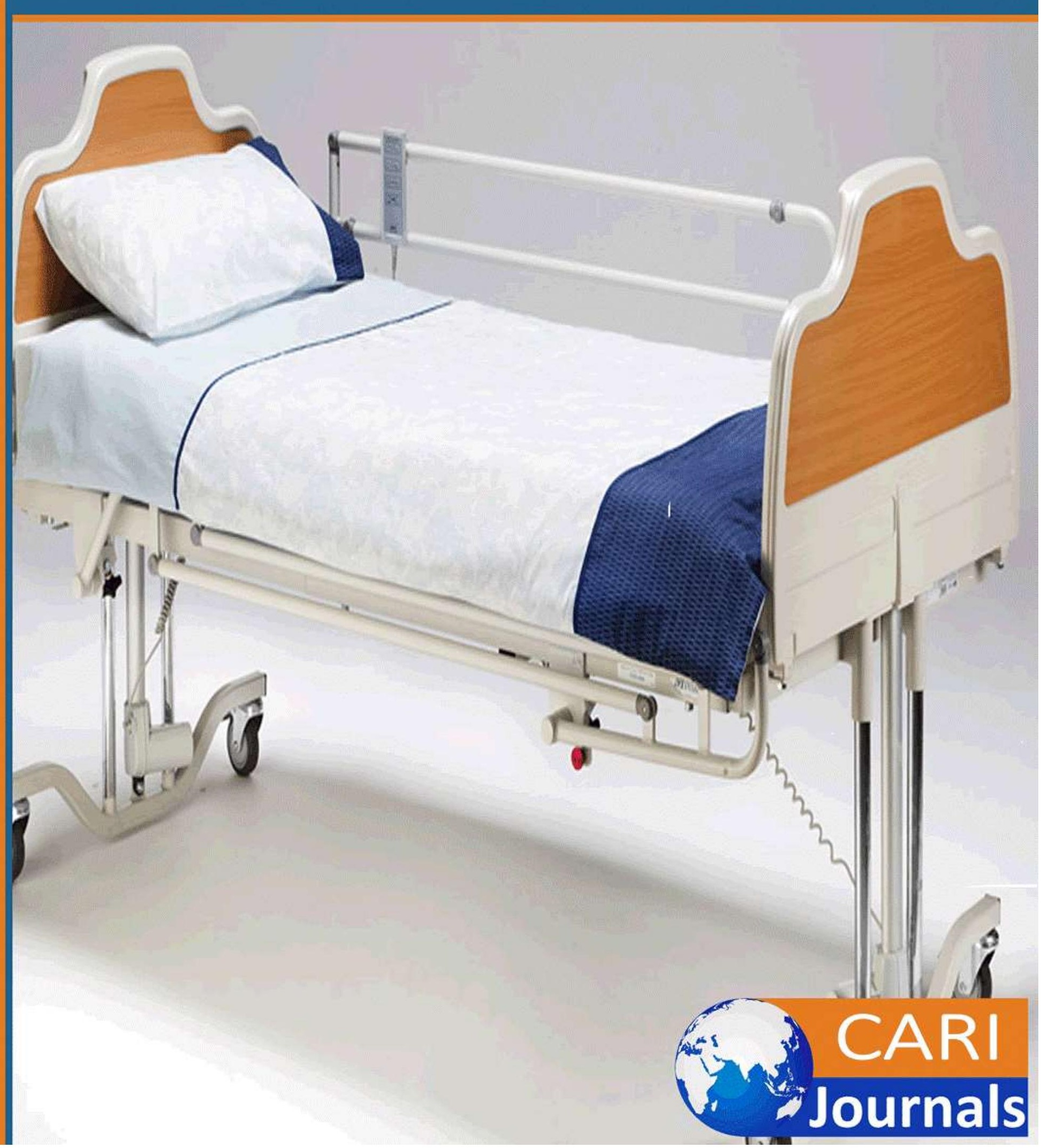




\title{
Prevalence, indicators and complications associated with manual vacuum aspiration at the University of Port Harcourt Teaching Hospital.
}

\author{
${ }^{1}$ Mube W. A., ${ }^{2 *}$ Gbaranor K.B., ${ }^{1}$ Oriji V. K., ${ }^{1}$ Oranu E. O., ${ }^{3}$ Gilbert U. D., ${ }^{4}$ Amadi N. C., \\ ${ }^{2}$ Emegara G. I., ${ }^{2}$ Wami-Amadi C. F., ${ }^{2}$ Nonju I. I, ${ }^{2}$ Oriji E. I. \\ ${ }^{1}$ Department of Obstetrics and Gynaecology, University of Port Harcourt Teaching Hospital, \\ Port Harcourt, Nigeria \\ ${ }^{2}$ Department of Human Physiology, College of Medical Sciences, Rivers State University, \\ Port Harcourt, Nigeria. \\ ${ }^{3}$ Ministry of Health, Rivers State, Nigeria \\ ${ }^{4}$ Department of Nursing Science, College of Medical Sciences, Rivers State University, Port \\ Harcourt, Nigeria. \\ *Corresponding author: Dr. Gbaranor, Kekii Barinua \\ Department of Human Physiology, College of Medical Sciences, \\ Rivers State University \\ Port Harcourt, Nigeria. \\ Phone: +2348037414186
}

Email: barinua.gbaranor@ust.edu.ng

\begin{abstract}
Manual vacuum aspiration is employed for the evacuation of retained products of conception or incomplete abortion. A five-year review of manual vacuum aspiration was conducted at the University of Port Harcourt Teaching Hospital from January 2012 to January 2017. The aim of this study is to evaluate prevalence, indicators and complications associated with manual vacuum aspiration at University of Port Harcourt Teaching Hospital. The data was collected from the manual vacuum aspiration book. The study revealed that 1453 patient had Gynaecological Surgeries, out of which 320 had manual vacuum aspiration, putting the prevalence of manual vacuum aspiration at $20.7 \%$. The mean gestational age and patients age were $11.10 \pm 3.69$ and $30.07 \pm 5.62$. The distributions of the indications for manual vacuum aspiration were incomplete miscarriage 318 (99.40\%), missed abortion $2(0.60 \%)$. No complication was documented for all the manual vacuum aspiration done. There was no significance in the maternal age and or gestational age predicting manual vacuum aspiration. Manual vacuum aspiration was considered a highly effective, simple and necessary gynaecological procedure with little or no complication. Training of medical personnel on manual vacuum aspiration procedure is strongly recommended to ensure a safe and effective uterine evacuation. The statistical analysis was carried out using Chi square test.
\end{abstract}

Key words: Prevalence, Indicators, Complications, Associated, manual vacuum 


\section{Introduction}

Manual vacuum aspiration (MVA) is a gynaecological procedure employed by specialists to evacuate products of retained conception. Application of MVA have saved several lives, particularly those women who took medications before seeking medical attention from the specialist. Manual vacuum aspiration is a simple gynaecology procedure carried out to evacuate product of conception from the uterus through a cannula attached to a hand-held manual vacuum source. ${ }^{1}$

The manual vacuum aspirator uses a combination of a specifically designed syringe and graded cannula to generate negative suction to the uterine cavity. ${ }^{1,2}$ The manual vacuum aspirator is fashion in a way that it holds its vacuum until the aperture is unlocked, once primed, it can be operated with one hand. ${ }^{1,2}$ The aspirator produces $60 \mathrm{mmHg}$ of negative pressure which decreases as the syringe fills up with products of conception. ${ }^{1}$ The manual vacuum aspirator functions in removal of products of conception which includes: embryo, membranes, chorionic villi (future placenta) and other particles or tissues in the uterine cavity. ${ }^{1,2}$ Studies demonstrate that the efficacy of manual vacuum aspiration is comparable to electric vacuum aspiration and is successful in approximately 99 percent of cases for management of early - elective abortion and management of early pregnancy loss ${ }^{3}$.

Manual vacuum aspiration is used in the management of early pregnancy loss, missed abortion, or persistent gestational sac and its use has been reported to be safe and effective for this indication $^{1-7}$. Manual vacuum aspiration can also be used in the elective termination of early pregnancies between $5-12$ weeks gestation with high safety and effectiveness ${ }^{1,8}$. When used in conjunction with Mifeprostone and misoprostol 95\% success is achieved. However, when there is persistent gestational sac, prolonged bleeding or incomplete uterine evacuation, manual vacuum aspiration achieves a success rate of $97 \% .^{1,8}$

The manual vacuum aspirator can also be used in the evacuation of residual moles and in obtaining endometrial sampling for histological evaluation. ${ }^{1,8,9}$

There are no contraindications for aspiration of the uterus using manual vacuum aspiration up to 12 weeks of gestation, meanwhile, it should not be used for endometrial biopsy in the case of suspected pregnancy and should be used with caution in women who have uterine anomalies, coagulation problems, active pelvic infection, extreme anxiety and any condition causing the patient to be medically unstable. ${ }^{1,10}$ Life threatening conditions must be addressed and managed before uterine aspiration. ${ }^{1,10}$

Complications may be noted during uterine evacuation when manual vacuum aspirator is used, the overall complication rate is about $2 \% .^{10,11}$ A significant complication of manual vacuum aspiration is the incomplete evacuation of the uterus. To reduce this risk, at the end of the procedure there should be a careful examination of the products of conception and during the procedure, complete evacuation usually presents with foamy red products in the cannula, gritting feel in the uterus, uterine contraction around the cannula and increased cramping perceived by the patient. ${ }^{1}$ Other complications includes uterine perforation which mostly occurs during cervical dilatation or in the presence of a retroverted uterus, cervical laceration may occur due to inappropriate dilatation or insertion of the cannula and if treatment is needed, haemostatic agents like silver nitrate may be sufficient for minor tears but in rare situations, suturing is needed. ${ }^{1,11}$ Haemorrhage is rare but can occur and its treatment depends on its severity. Pelvic infection is a risk and a non-touch technique should be used during the insertion of the cannula to avoid it touching the vaginal wall and aiding the transfer of micro-organism 
into the endometrial cavity and when this happens the treatment of the infection depends on its site. $^{1,11}$

A retrospective review of manual vacuum aspiration procedure on 672 patients who had first trimester miscarriage in University of Maiduguri Teaching Hospital between June 2007 to July 2012 showed that $74 \%$ of the patient were between 20 to 24years with a mean of $27 \pm 4$ years, $88 \%$ of the patient had miscarriage occurring between $7-12$ weeks of gestation, incomplete abortion accounted for $88.1 \%$ of the indication for the procedure which was the highest, vaginal bleeding $(94.6 \%)$ was the commonest complaints and $76.1 \%$ of the patient were not counselled for post abortal contraception and there was no recorded immediate complication following the procedure. Therefore, manual vacuum aspiration was considered to be a safe procedure. ${ }^{16}$ In a retrospective study on the experience with manual vacuum aspiration in JOS Nigeria, between January 1992 and December 2002 revealed that there were 307 (21.5\%) manual vacuum aspirations among 1428 gynaecology patients seen during the study period and the mean age was 27.6years. Incomplete abortion was the indications for manual vacuum aspiration in $85.3 \%$ of the cases, missed abortion in $7.8 \%$, and evacuation of molar pregnancies $6.2 \%$, sedation with pentazone was the mode of pain control in all cases of incomplete abortion (85.3\%). All cases of incomplete abortion spent less than 24hours on admission and there were no recorded major morbidities following the procedure. Hence manual vacuum aspiration was considered safe, simple and cost effective. ${ }^{17}$

\section{Materials and Methods}

A five-year review of manual vacuum aspiration was conducted at the University of Port Harcourt Teaching Hospital between January 2012 to January 2017. The retrospective descriptive study was carried out at the Obstetrics and Gynaecology Department of the University of Port Harcourt Teaching Hospital from January 2012 to January 2017. The data of all women who had manual vacuum aspirating were collated from the manual vacuum aspirating book using a designed proforma and analyzed with Chi square test.

\section{Manual Vacuum Aspiration Procedure}

In carrying out a manual vacuum aspiration procedure, the diagnosis and procedure is explained to the patient and an informed consent is obtained. ${ }^{1,13}$ Routine investigations such as full blood count to assess the haemoglobin level, white blood cell count and platelet level is done, grouping and cross matching of blood is also done especially if the patient is in shock. The instrument is assembled and charged to ascertain the vacuum, the patient is then asked to empty her bladder and a bimanual examination is done to confirm uterine size and position. A bivalved speculum is inserted to expose the cervix and the cervix is cleaned with antiseptic. Prophylactic antibiotics (Doxycycline 100mg 30minutes before and 200mg after the procedure) given. A paracervical block is given or other forms of anaesthesia given. If the cervix is not sufficiently dilated, a mechanical dilator or progressively larger cannula is used to dilate the cervix. A tenaculum is used to stabilize the cervix and a uterine sound is inserted to estimate the uterine depth. The appropriate size cannula is inserted through the cervical Os into the uterine cavity until it touches the fundus and then withdrawn slightly, while applying traction to the tenaculum. The canula is attached to the aspirator and the vacuum is released by pressing the valve buttons. The content of the uterus is evacuated by using the manually generated negative pressure and gently and slowly rotating the cannula 180 degrees in each direction in each direction while using a gentle in and out motion. For endometrial biopsy, the tissue is aspirated by moving the cannula gentle back and forth along the uterine wall, taking 
the appropriate sample. When the suction is complete, depress the buttons and withdraw the instrument, the above suctioning procedure is continued until the signs which indicate that the uterus is empty is noted. ${ }^{1,11}$ The procedure is considered not complete until the contents of the aspirator is emptied into a container and the tissues are inspected, contraception provided and samples sent to the laboratory for histopathology analysis. ${ }^{1-13}$ Adequate analgesia should be administered and broad spectrum antibiotics prescribed. ${ }^{1}$ The patient is recounselled on the extent of the procedure and the manual vacuum aspirator is processed or discarded according to local protocols. ${ }^{1}$

\section{Results}

The results from this study are presented in tables. The continuous variables were expressed as mean \pm standard deviation while categorical variables were presented as numbers and percentages $(\%)$.

Table 1 presented the mean \pm standard deviation of the maternal and gestational age. Table 2 and 3 presented the association between MVA and maternal and gestational age groups respectively.

In the study out of 320 manual vacuum aspirations done, 318(99.4\%) was for incomplete miscarriage and $2(0.6 \%)$ for missed miscarriage. Meanwhile, there was no documented complication in all the procedures.

Table 1: The descriptive characteristics of the maternal and gestational age

\begin{tabular}{lcccc}
\hline Variable & Observations & Minimum & Maximum & Mean \pm S.D \\
\hline Maternal age & 320 & 15 & 49 & $30.07 \pm 5.62$ \\
gestational age & 320 & 5 & 17 & $11.10 \pm 3.69$ \\
\hline
\end{tabular}

Note: $S . D=$ Standard deviation 
International Journal of Health, Medicine and Nursing Practice ISSN 2710-1150 (Online)

Vol.4, Issue No.1, pp $1-8,2022$

www.carijournals.org

Table 2: Association between maternal age groups and the presentation of the MVA (indications)

\begin{tabular}{ccccccc}
\hline & \multicolumn{2}{c}{ Indication } & & \multicolumn{2}{c}{ Chi-square analysis } \\
Gestational age & ICM (\%) & $\begin{array}{c}\text { M.A } \\
(\%)\end{array}$ & Total $(\%)$ & df & $\mathbf{X}^{2}$ & $\begin{array}{c}\text { p- } \\
\text { value }\end{array}$ \\
\hline $\mathbf{1 5 - 2 4 y r s}$ & $236(99.2)$ & $2(0.8)$ & $\mathbf{2 3 8}(\mathbf{7 4 . 4})$ & & & \\
$\mathbf{2 5 - 4 4 y r s}$ & $80(100)$ & $0(0)$ & $\mathbf{8 0}(\mathbf{0 . 2 5})$ & 2 & 0.721 & 0.681 \\
$\mathbf{4 5}$ and above & $2(100)$ & $0(0)$ & $\mathbf{2 ( 0 . 0 0 6 )}$ & & & \\
Total & $\mathbf{3 1 8}(\mathbf{9 9 . 4 )}$ & $\mathbf{2 ( 0 . 6 )}$ & $\mathbf{3 2 0}$ & & & \\
\hline
\end{tabular}

Note: ICM=Incomplete miscarriage, MA=Missed abortion.

$\mathrm{P}>0.05$ (No significant association)

Table 3: Association between gestational age groups and the presentation of the MVA (indications)

\begin{tabular}{ccccccc}
\hline & \multicolumn{2}{c}{ Indication } & & \multicolumn{2}{c}{ Chi-square analysis } \\
Gestational age & ICM (\%) & $\begin{array}{c}\text { M.A } \\
(\%)\end{array}$ & Total (\%) & df & $\mathbf{X}^{2}$ & $\begin{array}{c}\text { p- } \\
\text { value }\end{array}$ \\
\hline 1st trimester & $236(99.2)$ & $2(0.8)$ & $\mathbf{2 3 8 ( 7 4 . 4 )}$ & & & \\
2nd trimester & $81(100)$ & $0(0)$ & $\mathbf{8 1}(\mathbf{0 . 2 5})$ & 2 & 0.693 & 0.707 \\
3rd trimester & $1(100)$ & $0(0)$ & $\mathbf{1 ( 0 . 0 0 3 )}$ & & & \\
Total & $\mathbf{3 1 8 ( 9 9 . 4 )}$ & $\mathbf{2 ( 0 . 6 )}$ & $\mathbf{3 2 0}$ & & & \\
\hline
\end{tabular}

Note: ICM=Incomplete miscarriage, MA=Missed abortion.

$\mathrm{P}>0.05$ (No significant association)

\section{Discussion}

Manual vacuum aspiration is a widely acceptable method of evacuating the uterus following early pregnancy losses, persistent gestational sac and even in endometrial biopsy with little or no complication especially when performed by trained personnel and in a suitable environment ${ }^{1,7,9}$. The study revealed that 320 patients had manual vacuum aspiration at the University of Port Harcourt Teaching Hospital during the period under review and was due to the high patient load and presence of well-trained personnel's in the study centre. This number of patients is similar to 246 in the United Kingdom ${ }^{20}, 251$ in North East nigeria ${ }^{22}, 307$ in Jos ${ }^{17}$, 
573 in Sokoto $^{19}$ and 672 in maiduguri ${ }^{16}$ based on the large capacity and presence of gynaecologist at the centres. Meanwhile much lower values of $58{ }^{18}$ and $130{ }^{23}$ were documented in other studies conducted in secondary and non-specialized health facilities with low patients load. Therefore, the population and the quality of care rendered at a facility has a multiplier effect on subsequent attendance.

The total number of gynaecological procedures conducted in the University of Port Harcourt Teaching Hospital within the study period was 1543, which puts the prevalence of manual vacuum aspiration at the University of Port Harcourt in the past five years at $20.7 \%$ which is almost the same as $21.5 \%{ }^{17}$ documented at a health facility with similar patient population and expertise at conducting gynaecological procedures but dissimilar to $13.2 \%{ }^{22}$ as documented in a secondary health care facility with minimal patients load and limited expertise.

The mean age in years of the patients from this study is $30.07 \pm 5.62$ which is alike with $27.0 \pm 4$ ${ }^{16}, 27.0 \pm 6^{17}, 25.0 \pm 2.25^{21}$ which is expected as they fall within the reproductive age range of women with some risk of early pregnancy loss. ${ }^{5}$ The mean gestational age of the patient was $11.10 \pm 3.69$ and similar with $8.30 \pm 1.8^{23}$ which is expected as it falls within the same gestational age range when early pregnancy losses commonly occur for which uterine evacuation by manual vacuum aspiration is often performed. ${ }^{1,5}$

Also, the study revealed that, the distributions for the indications of manual vacuum aspiration were: incomplete miscarriage 318(99.40\%) and missed abortion 2(0.60\%). Similar values of incomplete miscarriages such as: $88 \%{ }^{16}, 85.3 \%{ }^{17}, 80 \%{ }^{22}$ and $75.8 \%{ }^{19}$ were noted in other studies and those noted for missed miscarriage in other studies were: $7.8 \%$ and $12 \%$. These values strongly show that majority of manual vacuum aspiration in our health facilities irrespective of the capacities are done for incomplete miscarriages as compared with other indications. ${ }^{1,4,5}$

The study shows that there was no noted complication in all the manual vacuum aspiration done within the study period and this agreed with previous studies ${ }^{16,17,18,22}$ which can be attributed to the quality of health personnel who performed the manual vacuum aspiration, as most of the studies were conducted in tertiary or highly specialist health facilities where resident doctors or consultants in gynaecology performed the procedures. Therefore, manual vacuum aspiration is safe and without complication when performed by a well-trained health personnel. However, some complications were noted in previous studies such as: pelvic inflammatory disease $(2.2 \%)^{19}$, incomplete uterine evacuation $(5.3 \%)^{20}$, cardiac arrhythmias $(2.9 \%)^{21}$, cervical injuries and vaso-vagal symptoms $(3.8)^{23}$. These complications occurred in health facilities with minimal expertise or where junior doctors (house officers) without adequate training in manual vacuum aspiration were allowed to perform the procedure. ${ }^{19}$

The research also revealed that maternal age and gestation of the patient when analyzed did not predict manual vacuum aspiration. Meanwhile analysis on complications associated with manual vacuum aspiration procedure in relationship with patient's age and gestational age was not possible as there was no documented complication associated without the procedures. The only significance difference observed from the study was noted in the indications for the procedure where a large percentage difference was noted between the percentage of incomplete miscarriage and missed miscarriage. 


\section{Conclusion}

Manual vacuum aspiration is an important and necessary gynaecological procedure used in the management of early pregnancy losses, retained products of conception, persistent gestational sac, retained placenta tissue and endometrial biopsy collection. The procedure is simple and safe and there were no associated complications in the hands of a well-trained medical personnel. Its use reduces significantly the health challenges associated with miscarriages, especially post abortal complication, therefore preserving the reproductive career of women.

\section{Recommendation}

1. Medical personnel's especially doctors should undergo training and re-training on how to use a manual vacuum aspirator effectively.

2. The manual vacuum aspiration kits, when recycled should be properly sterilized to prevent nosocomial infections.

3. The enabling environment should be put in place in any secondary and tertiary health facility to enhance smooth performance of manual vacuum aspiration.

4. When complications occur following manual vacuum aspiration, they should be managed appropriately to avoid further progression or refer to the secondary or tertiary health centres if the MVA was done in a health centre or health post.

5. All manual vacuum aspiration procedure done should be appropriately documented for proper reference and to enable further studies

\section{References}

1. Ekuma-Nkama NC. Manual Vacuum Aspiration. In: Umeora OUJ, Egbuji CC, Onyebuchi AK, Ezeonu PO (eds). Our Teachers a Comprehensive Textbook of Obstetrics and Gynaecology. $1^{\text {st }}$ Edition. Abakiliki: St. Benedict Printing and Publishing; 2017: 379 - 381.

2. www.ipas.org/en/what-we-do/comprehensive abortion care/MVA/MVAProducts.aspx. Retrieved on 1/07/2017.

3. Wen J. Cai QY, Deng F, Li YP. Manual Versus Electric Vacuum aspiration for first trimester abortion: a systematic review. BJOG. 2008; 115(1): 5-13.

4. Manual Vacuum Aspiration frequently asked questions page. Ipas website. Availableat:www.Ipas.org/library/TAQs/manualvacuum_Aspiration_frequently_asked_questions.aspx.Accessed 01/07/2017.

5. World Health Organization (WHO) 2003, Safe abortion. Technical and policy guidance for health systems. Geneva: WHO.

6. Warriner IK, Meirik O, Hoffman M, et al. Rates of Complications in first trimester manual vacuum aspiration done by doctors and mid-level providers in south Africa and Vietnam: a randomized controlled equivalent trail.Lancet. 2006;368:1965-72.

7. Hemlin J, Moller B. Manual vacuum aspiration, a safe and effective alternative in early Pregnancy termination. Actaobstet. Gynaecol Scand. 2001;80:563-67.

8. Creinin MD, Schwartz DL. Guido RS, Pymar HC. Early Pregnancy failure- Current management concepts. Obstet Gynecol Surv. 2001; 56(2):105-113. 
9. Baird, Traci L. and Susan K. Flinn. 2001. Manual vacuum aspiration: Expanding women access to safe abortion services. Chapel Hill NC. Ipas.MVA Label, United States, English. Ipas 2007.

10. Goldberg AB, Dean G., Kang MS., Youssof S, Darney PD. Manual versus electric vacuum aspiration for early first trimester abortion: a controlled study of complication rates. Obstet. Gygnecol. 2004; 103:101-7.

11. www.Ipas.org/en/resources/Ipas/20publications/step for performing-manual vacuumaspiration-using-the-ipas-MVA-Plus and Easy Grip-cannula.aspx. Retrieved 06/07/2017

12. Begum S. Rashi M, Jahan AA: A Clinical Study on management of incomplete abortion by manual vacuum aspiration (MVA) J. Enam Med Col. 2012; 2(1):24-28.

13. Cunningham, F, Leveno K. J., Bloom S. L., Spong C. Y., Dashe J.S., Hoffman B. L, Casey B. M. Sheffield J. S. (2013) “Abortion” Williams Obstetrics. McGraw-Hill.

14. Johns Hopkins manual of Gynaecology and Obstetrics $\left(4^{\text {th }}\right.$ e.d. $)$. Lippincott Williams \& Wilkins. 2012: 438-439.

15. www.who.int/reproductivehealth/unsafe_abortion/magnitude/en/retrieved 06/07/2017.

16. Isa B, Mairiga AG, Ibrahim SM, Bako BG, Usman HA. Experience with manual vacuum aspiration at University of Maiduguri Teaching Hospital. Borno Medical Journal .2013; 10 (2):31-35.

17. Josiah TM, Innocent OA, Ujah. Experience with Manual Vacuum aspiration in JOS, Nigeria. Tropical J of Obstet and Gynae. 2004; 21:100-103.

18. Gazvani R, Honey E, MacLennan FM, Templeton A. Manual Vacuum aspiration (MVA) in the management of first trimester pregnancy loss. Eur. J. Obstet Gynecol Reprod. Biol. 2004 ; 112 (2): 197 - 200.

19. https://www.researchgat.net/publication/272498818-A-review-of-manual-vacuumaspiration-at-UDUTH-Sokoto.

20. Milingos DS, Mathur M, Smith NC, Ashok PW. Manual Vacuum aspiration: a safe alternative for the surgical management of early pregnancy loss. BJOG. 2009;116(9): $1268-71$.

21. Ansari A, Abbas S. Manual vacuum aspiration (MVA) - A safe option for evacuation of first trimester miscarriage in cardiac patient. $\mathrm{J}$ of the Pakistan Med Asso. 2017;67:948 - 950 .

22. Kallima AA, Kawuma MB, Mainage AG, Bako B, Audu BM, Bimba J. Effectiveness of manual vacuum aspiration (MVA) in the management of first trimester miscarriage: Experience in a specialist centre in North-East Nigeria. Port Harcourt Med J. 2009; 3 (3): 45261.

23. Kumar V. Chester J, Gupta J. Shehmar M. Manual Vacuum aspiration under local anaesthesia for early miscarriage: 2 years experience in a University Teaching Hospital in UK. Gynaecol Surg J. 2013; 10:241 - 246 